\title{
Learning Natural Frequency And Resonance Using Wasted Water Bottle
}

\author{
Eko Nursulistiyo ${ }^{1}$ \\ \{ekonur.uad@gmail.com\} \\ Physics Education Study Program, Universitas Ahmad Dahlan, Yogyakarta, Indonesia ${ }^{1}$
}

\begin{abstract}
The water bottle can be used as learning media to teach physics. Finding its natural frequency and develop a procedure to show resonance phenomena are needed to use it in teaching and learning in the class. In this research, three bottles had been used. Using sound analysis free and tone generator installed on a mobile phone, we can detect the natural frequency of these three bottles and show the resonance phenomenon. "Fresh tea" bottle has a natural frequency in $186.3 \pm 0.6 \mathrm{~Hz}$. While Syrup bottle has a natural frequency in $133.8 \pm 0.6 \mathrm{~Hz}$ and "Pristine" bottle has a natural frequency in $203.4 \pm 1.2 \mathrm{~Hz}$. The step to perform a resonance phenomenon as follows: a). Open tone generator and click sweep generator, b). Change sweep to tone by click sweep button on the bottom left, c). Change the frequency by clicking the frequency in $\mathrm{Hz}$ and input the frequency, d). Play by clicking the bottom middle button, e). Move mobile phone speaker to the top of bottle mouth, f). Check the difference of sound volume at the top of the bottle and in other position. The relation between resonance frequency $(\mathrm{y})$ and the square of one per length of the empty collum in the bottle $(\mathrm{x})$ follow equation $\mathrm{y}=2298 \mathrm{x}-310.2$. $\mathrm{R}^{2}$ is equal to 0.952 , which shows that the equation produced in the graphic is strongly fit to the data. The relation between resonance frequency $(\mathrm{y})$ and the square of one per length of the empty collum (x) in bottle $y=4317 x+47.33 . R^{2}$ is equal to 0.996 , which shows that the relation the equation produced in the graphic is strongly fit to the data. The data is fit to the theory.
\end{abstract}

Keywords: natural frequency, resonance, water bottle

\section{Introduction}

Sound is an abstract learning material [1]. Visualizing and witnesses it can increase student understanding and experience about sound. But in most schools, the delivering method is almost the same. A teacher often only uses lecturing and not give the student an opportunity to witnesses the phenomena. The reason is various. Some of the teachers do not know how to bring that concept to reality. Others, they do not have time to prepare the learning material in the laboratory to experiment, or they do not have the tools. It needs a procedure and method that simple and can be done with quick preparation to experiment with the introduction of resonance concept for the student.

Resonance phenomena are the vibration of others object or system because of the vibration of other objects/systems. Some of the teachers use two tuning forks which has the same frequency. When one of them make a sound by hitting it, other will vibrate too. This phenomenon is because both have the same natural frequency. The phenomena happen too, when we have two pendulums with the same length. When one pendulum oscillates, another one will oscillate too. The natural frequency of a system or an object is precise. Two identical 
baseball stick may not have the same natural frequency. Two glasses windows or two drinking glasses with identical in shape may also have a different natural frequency too. Knowing the natural frequency of this glass object will make us understand how to break this glass using sound. Sounding tuning fork in the top of air column will produce resonace too [2]. But, commonly, the sound source used in the air column resonance experiment is the tuning fork having disadvantage of unoptimal resonance results due to the sound produced which is getting weaker [3]. Resonance occurs when two objects have the same natural frequency.

The water bottle can be found anywhere, easy to find, and very cheap, some of them can be found as trash for free. Blowing in the top of this water bottle at open can make a sound. The frequency of the sound depends on the depth of the column. When air is blown across a water bottle, the turbulent airflow across the open bottle interacts with the confined air and sets up an oscillation in the neck at a resonant frequency. The Helmholtz resonator applies to a large bottle with a small narrow neck[4]. Known as Helmholtz resonance, this phenomenon occurs when air is blown across containers with a wide range of cavity and neck shape [5]. Sound is produced only for specific values of the blowing velocity [6]. This frequency called resonance frequency in the open-end tube. Monteiro et all did experiment using the bottle to find the relationship between volume and natural frequency with blow the bottle which filled with water in various capacity [7]. But not all bottles resonate according to the Helmholtz equation [8]. This research is only to find a new way of teaching natural frequency and resonance using a water bottle. A good Helmholz resonator can be used to measure of water filled in it [9] and also can visualize the harmonic series of its pipe at ideal situation [1]. The bottle is a system of an open-end tube which follows equation 1 .

$$
f_{n}=\left(\frac{2 n-1}{4}\right) \frac{v}{l}
$$

With $f_{n}$ is resonance frequency, $v$ is the speed of sound in air, $l$ is the lenght of the collumn in open-end tube, and harmonics $n=1,2,3,4, \ldots$.

From equation 1

$$
f_{n} \approx v \approx \frac{1}{l}
$$

If the lenght of the collumn longer then the resonance frequency will be lower. Lenght of the collumn can be seen in figure 1 .

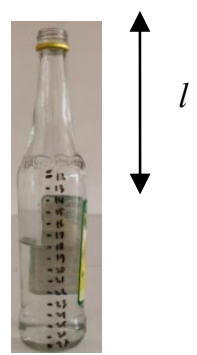

Figure 1. Lenght of the bottle column.

If volume of space in the collumn is equal to $V=A . l$ then

$$
f_{n} \approx \frac{1}{l} \approx \frac{1}{V}
$$

From equation 3 we can see that resonance frequency is lineary related to $1 / l$ and $1 / V$. This relation will be proved in experiment using water bottle. Futher experiment found by D. Megli [10], Balacandran [5], Ruiz [4] and A Eliot [8] that

$$
f_{n}=\frac{v}{2 \pi} \sqrt{\frac{A}{V l}}
$$


Where $A$ is the cross-sectional area of the neck. From this experiment the relation between resonance frequencies whit volume and lenght are linear as follows

$$
f_{n} \approx \frac{1}{\sqrt{l}} \approx \frac{1}{\sqrt{V}}
$$

Sound analyzer free is an application that can be used to determine the frequency and free. Using this application, combined with water bottle blowing, can perform variation in natural frequency phenomenon for the student. The tone generator is an application in android to produce sound with a specific frequency. Using this application sound with specific frequency match with the natural frequency of water bottle can be performed so resonance phenomenon can occur. This research aims to:

1. Determine the natural frequency of water bottle with sound analyzer free

2. Determine the procedure to perform resonance in water bottle using tone generator

3. Determine the relation between column lenght, empty space volume in the bottle to bottle resonance frequency on bottle which have a neck

\section{Methodology}

The object of this research is three bottles. These bottles are not identic. The shape is also different. Water bottle blows to produce sound, and the frequency is determined using sound analysis free installed on a mobile phone. These bottles have specification shows in table 1 . The picture of the water bottle is in Figure 2.

Table 1. Specification of water bottle

\begin{tabular}{|l|l|l|l|l|}
\hline Type of bottle & "Fresh tea" bottle & $\begin{array}{l}\text { "Agung" } \\
\text { Syrup bottle }\end{array}$ & $\begin{array}{l}\text { "Marjan" } \\
\text { Syrup Bottle }\end{array}$ & "pristine" bottle \\
\hline Material & Plastic & glass & glass & Plastic \\
\hline Column length & $23.9 \mathrm{~cm}$ & $27.4 \mathrm{~cm}$ & $27 \mathrm{~cm}$ & $21.3 \mathrm{~cm}$ \\
\hline Neck length & $2.0 \mathrm{~cm}$ & $9.5 \mathrm{~cm}$ & $11.5 \mathrm{~cm}$ & $2.5 \mathrm{~cm}$ \\
\hline Body length & $21.9 \mathrm{~cm}$ & $17.9 \mathrm{~cm}$ & $15.5 \mathrm{~cm}$ & $18.8 \mathrm{~cm}$ \\
\hline Body Diameter & $6.3 \mathrm{~cm}$ (not equally) & $6.4 \mathrm{~cm}$ & $5.5 \mathrm{~cm}$ & $6.0 \mathrm{~cm}$ \\
\hline Mouth diameter & $2.0 \mathrm{~cm}$ & $1.8 \mathrm{~cm}$ & $2 \mathrm{~cm}$ & $2.5 \mathrm{~cm}$ \\
\hline $\begin{array}{l}\text { Producing sound } \\
\text { difficulties }\end{array}$ & medium & easy & easy & hard \\
\hline
\end{tabular}

In this research, mobile phone "Vivo V15Pro" is used. Software tone generator and sound analysis free are installed. The experiment is done in the night to avoid another sound that will include in the sound study.

\section{A. Determine the natural frequency of bottles}

Every bottle is blown to produce sound. This sound will represent the natural frequency of the system in the bottle. These sounds are analyzed using sound analysis free application in android to see the highest peak of the sound graphics. This highest peak of the frequency is the natural frequency of the system in the bottle.

\section{$B$. Determine the procedure to perform resonance in water bottle using tone generator}

After the natural frequency found, tone generator installed and will be used to produce sound. Sound with a specific frequency is created. The frequency of the sound in tone generator sets to the natural frequency of the bottle. Close the speaker of the mobile phone to bottle and see 
what happened. If the resonance occurs, write down the practical procedure for teacher or student to perform this experiment.

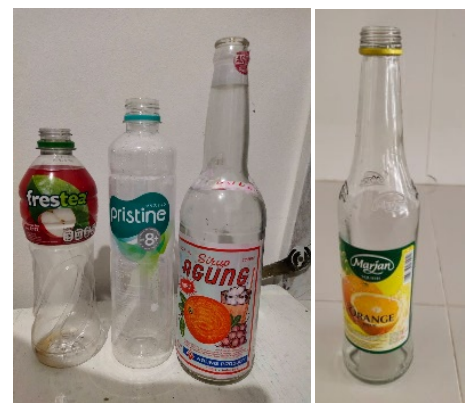

Figure 2. Bottle as object in this research

C. Determine the relation between collumn lenght, empty space volume in the bottle to bottle resonance frequency on bottle which have a neck

Using the easiest bottle to perform sound with blowing, the variance of length and volume of space in the bottle is varied. Graphics between frequency versus $1 /$ lenght and $1 /$ volume created. The relation between resonance frequency and length or volume analyzed using $\mathrm{ms}$ excel.

\section{Result and disscussion}

\section{A. Determine the natural frequency of bottles}

Sound analysis free is an smartphone application to analyze the frequency of the sound in realtime. Before using this, calibration is done using frequency from audacity in the laptop to produce $440 \mathrm{~Hz}$ tone and use the application to detect the sound frequency. The result is the frequency detected in exact $440 \mathrm{~Hz}$ (Fig. 3). The sound application free from Google Playstore can be used to determine sound frequency real-time with high precision.

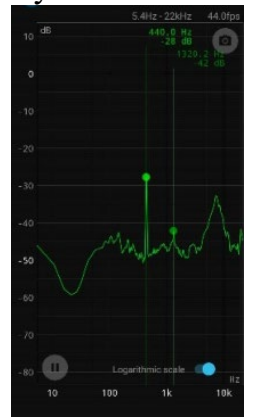

Figure 3. Frequency detected by sound analysis application in $440 \mathrm{~Hz}$ (the same as resources frequency)

The results of sound frequencies of three bottle that blow to produce sound are in table 2. It can be shown that "fresh tea" bottle has a natural frequency in $186.3 \pm 0.6 \mathrm{~Hz}$. While "Agung" 
Syrup bottle has a natural frequency in $133.8 \pm 0.6 \mathrm{~Hz}$, "Marjan" Syrup bottle has a natural frequency in $156.1 \pm 0.3 \mathrm{~Hz}$, and "Pristine" bottle has a natural frequency in $203.4 \pm 1.2 \mathrm{~Hz}$.

Table 2. Natural Frequency of water bottle

\begin{tabular}{|c|c|c|c|c|}
\hline No & $\begin{array}{l}\text { "Fresh tea"bottle } \\
(\mathrm{Hz})\end{array}$ & $\begin{array}{l}\text { "Agung" } \\
\text { Syrup bottle } \\
(\mathrm{Hz})\end{array}$ & $\begin{array}{l}\text { "Marjan" } \\
\text { Syrup Bottle } \\
(\mathrm{Hz})\end{array}$ & $\begin{array}{l}\text { "Pristine" } \\
\text { bottle (Hz) }\end{array}$ \\
\hline 1 & 185.8 & 134.3 & 156.4 & 203.4 \\
\hline 2 & 186.1 & 133.1 & 156.1 & 203.5 \\
\hline 3 & 187 & 133.3 & 155.6 & 204.7 \\
\hline 4 & 186.9 & 133.6 & 156.4 & 203.9 \\
\hline 5 & 185.7 & 134.6 & 155.9 & 201.5 \\
\hline Mean & 186.3 & 133.8 & 156.1 & 203.4 \\
\hline $\mathrm{Sd}$ & 0.6 & 0.6 & 0.3 & 1.2 \\
\hline
\end{tabular}

From the graphics of the sound of the bottle in sound analysis, it can be seen that the natural frequencies have the highest peak (figure 4). Another peak is the second harmonics, third harmonics, and so on. It is very easy to use this application. Push the button in the bottom left near 0 points to collect data and stop the analysis when sound from the resource (water bottle) occur. This simplicity is needed for teacher or student to do this experiment. Student or teacher can perform this activity in the class easily.

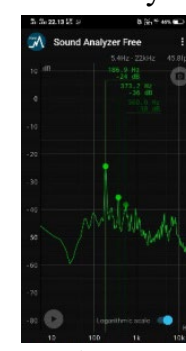

a)

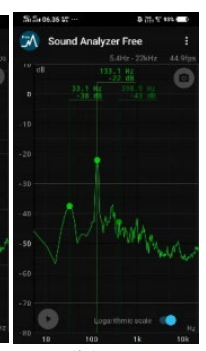

(b)

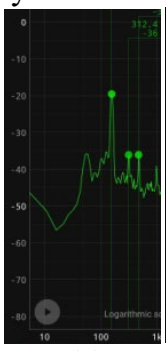

(c)

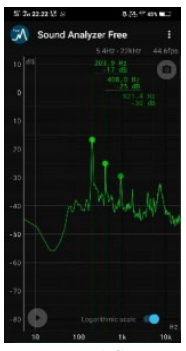

(d)

Figure 4. Graphics of natural frequency (a). "Fresh tea" Bottle, (b). "Agung" Syrup bottle, (c). "Marjan" syrup bottle, (d). "Pristine" bottle

$B$. Determine the procedure to perform resonance in water bottle using tone generator

Tone generator produces sound with exact frequency (figure 5). This application can be downloaded for free in Google Playstore. The step to produce sound as follows:Open tone generator and click sweep generator:

1. Change sweep to tone by click sweep button on bottom left.

2. Change the frequency by clicking the frequency in $\mathrm{Hz}$ and input the frequency

3. Play by clicking the bottom middle button

The sound will appear in exact input frequency. Set the frequency in the natural frequency of the bottle and play it. Moving mobile phone speaker to the mouth of the bottle make sound louder than before. This phenomenon is resonance. It is a unique way to perform resonance concept using this way, and the student and teacher can do this. 


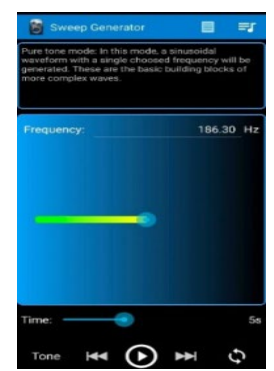

Figure 5. Produce $186.3 \mathrm{~Hz}$ frequency using tone generator

C. Determine the relation between collumn lenght, empty space volume in the bottle to bottle resonance frequency on bottle which have a neck

In the experiment of determining the natural frequency of the bottle, the easiest way to produce sound and the best natural frequency is in "Marjan" syrup bottle. This bottle has 470 $\mathrm{ml}$ in volume. The length of the column measured from the top of the bottle/mount of the bottle. Water poured into the bottle to fill the bottle and make the column length variation. The bottle blows so we can find its natural frequency which is the resonance frequency of the system. The result of this experiment is in figure 6 and figure 6 .

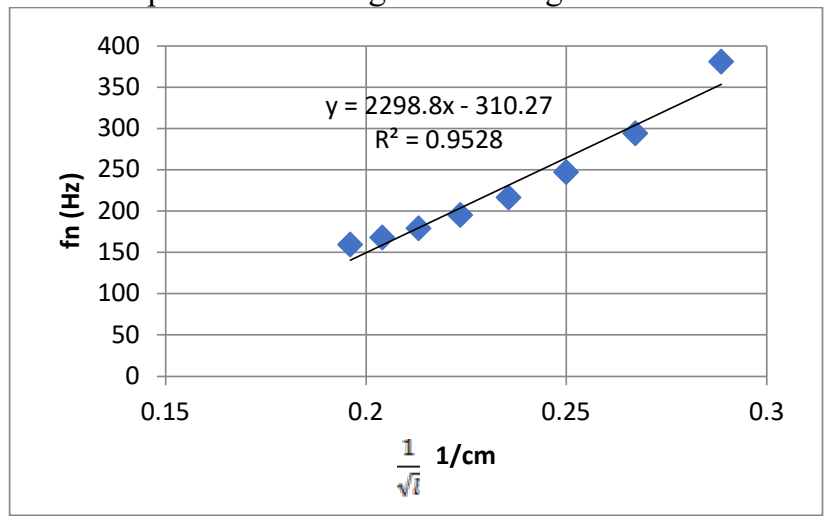

Figure 6. Relation between $\frac{1}{\sqrt{l}}$ and resonance frequencies

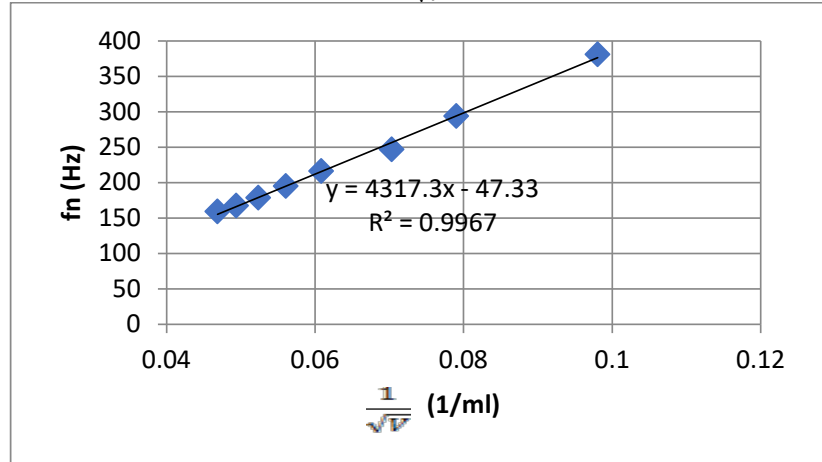

Figure 7. Relation between $\frac{1}{\sqrt{V}}$ and resonance frequencies

From graphics in figure 6 , we can see that resonance frequency is linearly related to the square of one per length column. This variation is the prove of equation 3 . There is a slight difference 
in the data in low light. This slight difference does not happen after second data which is taken in the same diameter. The first data and the second data is in the transition zone. In the bottle, there is a transition between the body with the high diameter and the neck which has a shorter diameter. This situation is affecting the resonance frequency. The diameter of the column affects the resonance frequency. The graphic in figure 6 gives equation $y=2298 \mathrm{x}-310 . \mathrm{R}^{2}$ is equal to 0.952 , which shows that the equation produced in the graphic is strongly fit to the data.

Figure 7 also prove that natural frequency linearly related to the square of one per volume of the bottle. This is the proof of equation 3. The graphic in figure 7 gives equation $y=4317 x+$ 47. $\mathrm{R}^{2}$ is equal to 0.996 , which shows that the relation the equation produced in the graphic is strongly fit to the data. Equation 4 and 5 are proved.

\section{Disscussion}

The step to find the natural frequency of the any water bottle is as follows:

1. Blow the bottle until have high volume sound

2. Detect natural frequency by looking the highest peak

3. Determine the natural frequencies of the bottle

This step can be used also when the bottle is not empty. The more depth will lower the natural frequencies if there is a water inside the bottle. This will lead us to open-end tube resonance concept. In this step also noted that the higher diameter of the mouth bottles the more difficult to produce sound at its natural frequencies. The material and length of the neck also influence the natural frequency. More exploration about it can be done in another research.

The step to perform resonance phenomenon as follows:

1. Open tone generator and click sweep generator

2. Change sweep to tone by click sweep button on bottom left.

3. Change the frequency by clicking the frequency in $\mathrm{Hz}$ and input the frequency

4. Play by clicking bottom middle button

5. Move mobile phone speaker to the top of bottle mouth

6. Check the difference of sound volume at the top of the bottle and in other position

The sound volume increase when mobile phone speaker place at the top of the mounted bottle. The bottle will begin to vibrate. Contacting the bottle with a finger will make feeling about this sensation of vibration. This happened when the resonance phenomenon appeared.

From figure 6 and 7, it can be seen that equation three is proved. But because there is a transition zone in the bottle between high-low diameter, there are slight differences in the data at lower length. The effect of diameter in resonance frequencies also appear. This results also follow the result of the experiment did by Boelkes and Ingrid [11]. The same experiment also found by Luftiah et al. [12] and Amrani [13]. The diameter of the pipe does affect the resonance frequency. The equation appears in the graphics shows strongly fit to the data. But in another experiment, $\mathrm{R}$ Nave[14] found that the relation of air volume with resonance frequency is not in linear. The relationships of it are linear in the graphics of $f$ vs $\frac{1}{\sqrt{V}}$ or $f$ vs $\frac{1}{\sqrt{l}}$. Equation 4 and 5 are proved..

\section{Conclusion}

1. "Fresh tea" bottle has natural frequency in $186.3 \pm 0.6 \mathrm{~Hz}$. While Syrup bottle has natural frequency in $133.8 \pm 0.6 \mathrm{~Hz}$ and "Pristine" bottle has natural frequency in $203.4 \pm 1.2 \mathrm{~Hz}$. The step to find the natural frequency of the any water bottle is as follows: 
a) Blow the bottle until have high volume sound

b) Detect natural frequency by looking the highest peak

c) Determine the natural frequencies of the bottle

2. The step to perform resonance phenomenon as follows:

a) Open tone generator and click sweep generator

b) Change sweep to tone by click sweep button on bottom left.

c) Change the frequency by clicking the frequency in $\mathrm{Hz}$ and input the frequency

d) Play by clicking bottom middle button

e) Move mobile phone speaker to the top of bottle mouth

f) Check the difference of sound volume at the top of the bottle and in other position

3. The relation between resonance frequency $(y)$ and square of one per lengt of the empty collum in bottle $(x)$ follow equation $y=2298 x-310 . R^{2}$ is equal to 0.952 which shows that the equation produced in the grahic is strongly fit to the data. The relation between resonance frequency $(y)$ and square of one per lengt of the empty collum $(x)$ in bottle $y=4317 x+47 . R^{2}$ is equal to 0.996 which shows that the relation the equation produced in the grahpic is strongly fit to the data. The data is fit to the theory.

\section{References}

[1] R. Jaafar, S. K. Ayop, A. T. Ismail@Illias, K. K. Hon, A. N. M. Daud, and M. H. Hashim, "Visualization of Harmonic Series in Resonance Tubes Using a Smartphone," Phys. Teach., 2016.

[2] J. Nelson and J. Nelson, "A New Look at an Old Activity: Resonance Tubes Used to Teach Resonance," Phys. Teach., 2017.

[3] E. Purjiyanta, L. Handayani, and P. Marwoto, "Development of an ICT-Based Air Column Resonance Learning Media,” in Journal of Physics: Conference Series, 2016.

[4] M. J. Ruiz and E. Boysen, "Flutist produces four resonances with a single bottle," Phys. Educ., 2017.

[5] A. Balachandran, F. Watanabe, and J. Lim, "Helmholtz Resonance in a Water Bottle," vol. 5, no. January, pp. 3-6, 2011.

[6] L. Mahadevan, "Blowing on a Bottle : Probing the Sound Generation Mechanics of Simple Resonators," no. January, 2015.

[7] M. Monteiro, C. Stari, C. Cabeza, and A. C. Marti, "A bottle of tea as a universal Helmholtz resonator," Phys. Teach., 2018.

[8] A. Elliott, "Resonance in Bottles with Different Shapes," ISB J. Phys., 2012.

[9] E. S. Webster and C. E. Davies, "The use of helmholtz resonance for measuring the volume of liquids and solids," Sensors, 2010.

[10] Darrell Megli, “AIR RESONANCE IN A PLASTIC BOTTLE,” Oct. 1965.

[11] T. Boelkes and I. Hoffmann, "Pipe Diameter and End Correction of a Resonant Standing Wave," ISB J. Phys., vol. 5, no. January, pp. 1-3, 2011.

[12] A. Lutfiyah, A. S. Adam, N. Suprapto, A. Kholiq, and N. P. Putri, "Correction factors in determining speed of sound among freshmen in undergraduate physics laboratory," in Journal of Physics: Conference Series, 2018.

[13] D. Amrani, "A comparative study of sound speed in air at room temperature between a pressure sensor and a sound sensor," Phys. Educ., 2013.

[14] R. Nave, "Coke Bottle Cavity Resonance." . 